\title{
Overcoming Resistance to Combination
} Radiation-Immunotherapy: A Focus on Contributing Pathways Within the Tumor Microenvironment

\section{OPEN ACCESS}

Edited by:

Patrik Andersson,

Massachusetts General Hospital and

Harvard Medical School,

United States

Reviewed by:

Udo S. Gaipl,

University Hospital Erlangen, Germany

Rodabe N. Amaria,

University of Texas MD Anderson

Cancer Center, United States

*Correspondence:

Sana D. Karam

sana.karam@ucdenver.edu

Specialty section:

This article was submitted to Cancer Immunity and Immunotherapy,

a section of the journal

Frontiers in Immunology

Received: 01 November 2018 Accepted: 20 December 2018 Published: 31 January 2019

Citation:

Darragh LB, Oweida AJ and Karam SD (2019) Overcoming

Resistance to Combination Radiation-Immunotherapy: A Focus on Contributing Pathways Within the Tumor Microenvironment. Front. Immunol. 9:3154. doi: 10.3389/fimmu.2018.03154

\author{
Laurel B. Darragh, Ayman J. Oweida and Sana D. Karam* \\ Department of Radiation Oncology, School of Medicine, University of Colorado, Aurora, CO, United States
}

Radiation therapy has been used for many years to treat tumors based on its DNA-damage-mediated ability to kill cells. More recently, RT has been shown to exert beneficial modulatory effects on immune responses, such as triggering immunogenic cell death, enhancing antigen presentation, and activating cytotoxic $T$ cells. Consequently, combining radiation therapy with immunotherapy represents an important area of research. Thus far, immune-checkpoint inhibitors targeting programmed death-ligand 1 (PD-L1), programmed cell death protein 1 (PD-1), and cytotoxic T-lymphocyte-associated protein 4 (CTLA-4) have been the focus of many research studies and clinical trials. The available data suggest that such immunotherapies are enhanced when combined with radiation therapy. However, treatment resistance, intrinsic or acquired, is still prevalent. Various theories as to how to enhance these combination therapies to overcome treatment resistance have been proposed. In this review, we focus on the principles surrounding radiation therapy's positive and negative effects on the tumor microenvironment. We explore mechanisms underlying radiation therapy's synergistic and antagonistic effects on immune responses and provide a base of knowledge for radio-immunology combination therapies to overcome treatment resistance. We provide evidence for targeting regulatory $T$ cells, tumor-associated macrophages, and cancer-associated fibroblasts in combination radio-immunotherapies to improve cancer treatment.

Keywords: immunotherapy, radiation therapy (RT), myeloid derived suppressor cell (MDSC), regulatory T (Treg) cell, tumor microenvironment (TME), immunotherapy resistance, cancer associated fibroblast (CAF)

\section{INTRODUCTION}

Radiation therapy (RT) represents standard-of-care treatment for more than half of all cancer patients (1). RT was originally used for its ability to induce doublestranded DNA damage resulting in cell death via apoptosis, necrosis, autophagy, mitotic catastrophe, or replicative senescence $(2,3)$. But RT can also modulate the immune system and the tumor microenvironment (TME) in a dose-dependent manner (4-6). Our increased knowledge of the positive immune-modulating effects of RT has led 
to the development of novel combination therapies. Several preclinical studies have shown that combining RT with immunotherapy (IT) can result in better local and systemic tumor control (5). Combining RT with anti-CTLA-4 therapy (7-10), anti-PD-1 (11-13), or anti-PD-L1 therapy (14-16), with RT doses ranging from 2 to $20 \mathrm{~Gy}$ in single and fractionated regimens, has resulted in prolonged survival and reduced tumor growth in preclinical tumor models (17). Emerging data from clinical trials combining RT and IT have also shown promise (18-21). Most recently, a Phase II clinical trial in which patients with locally advanced non-small cell lung cancer (NSCLC) or metastatic disease were treated with RT followed by pembrolizumab (anti-PD-1) found that this combination prolonged overall survival by 19.8 weeks (NCT02407171). Administration of nivolumab (anti-PD-1) before RT in another Phase II clinical trial looking at advanced NSCLC was shown to increase the 18 months survival of patients by $29 \%$ (22). Similarly, RT increased the effectiveness of PD-L1 inhibition in a retrospective study of recurrent/metastatic nasopharyngeal carcinoma (23). Although combining IT with RT has shown promising improvements in survival in these clinical trials, patients eventually relapse, and durable responses are rare (24). Several parameters can influence the response to IT and RT combinations, including RT dose, sequencing, and tumor oncogenic and immune composition. This variable success rate is thought to be caused by resistance-regrowth of the tumor-and is still common in most patients treated with radio-immunotherapy as some cancers like head and neck squamous cell carcinoma have a low response rate of $13 \%$ (25). By considering the cancer tumor microenvironment (TME) and its components, and how to specifically modulate them with RT and IT, we can potentially determine how to override resistance to radio-immunotherapy and improve outcomes.

Various elements of the TME can prevent effective lymphocyte priming, reduce immune cell infiltration, and suppress effector cell function that can lead to a failure of the host to reject tumors (26). These elements identify several potential mechanisms that could affect the efficacy of radio-immunotherapy: suppressive immune cells including regulatory $\mathrm{T}$ cells (Tregs), macrophages, or myeloid derived suppressor cells (MDSC); lack of antigen stimulation/co-stimulation for dendritic cells (DCs) leading to inadequate $\mathrm{T}$ cell priming; physical barriers such as a thick extracellular matrix (ECM) produced by fibroblasts around tumor tissues preventing immune cell entry into tumors; and exhausted or short-lived activation of antigen-specific cytotoxic $\mathrm{CD}^{+} \mathrm{T}$ cells through activation of immune checkpoints like PD-1. Although tumor-intrinsic factors also play an important role in mediating growth and survival of the primary tumor (27), the focus of this review is on how elements of the TME can impact treatment outcomes, how RT modulates the immune TME, and potential immunotherapies that could improve RT's effects (as shown in Figure 1). This will provide a foundation for developing rational targeted ITs aimed at reducing the development of resistance when combined with RT. Further, it presents a rationale for shifting from broad targeting of immune checkpoint receptors to targeting of

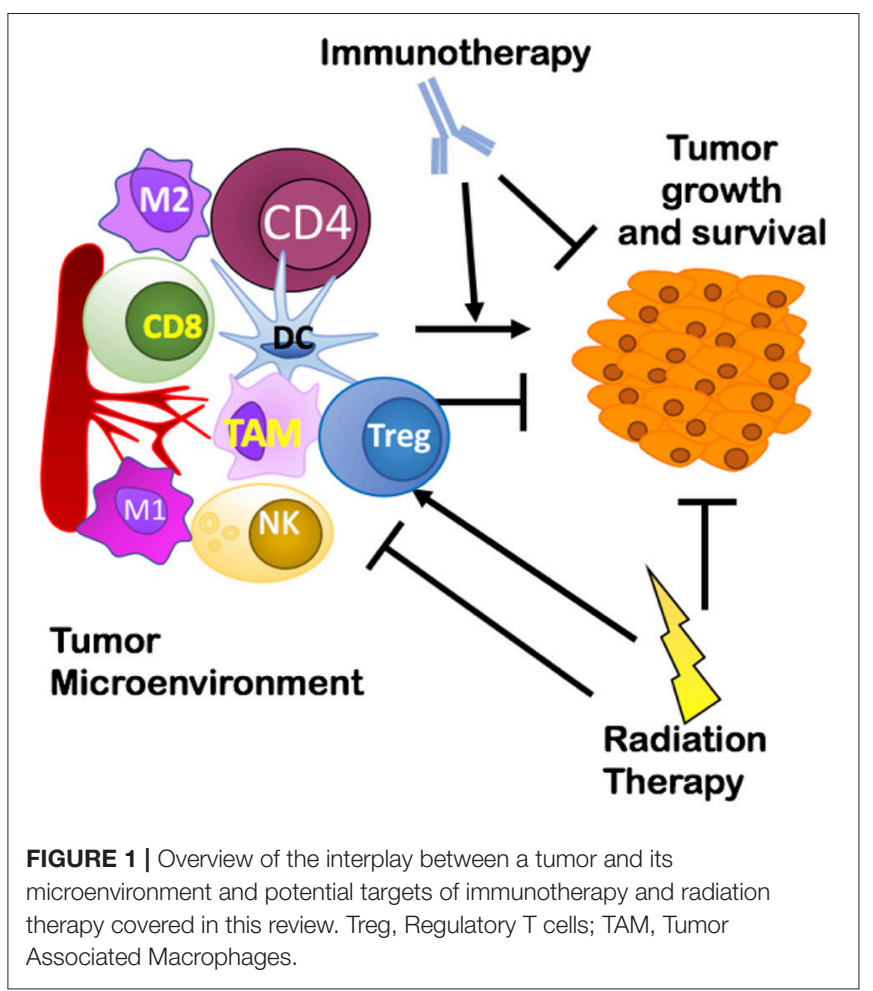

regulatory $\mathrm{T}$ cells, tumor-associated macrophages, and cancerassociated fibroblasts as specific targets for combination radioimmunotherapies. We conclude by suggesting that a thorough understanding of the biological pathways underlying known interactions between RT and various immune targets is and will continue to be invaluable for informing design of combination radio-immunotherapies to improve cancer treatment.

\section{HIGHLIGHTING RT'S DELICATE BALANCE BETWEEN PROMOTING IMMUNOSUPPRESSION AND TUMOR CYTOTOXICITY}

To maximize the therapeutic ratio, it is important to establish a combination of ITs that activate pathways to promote anti-tumor immunity and effector $\mathrm{T}$ cell function while limiting pathways that mediate an immunosuppressive TME. Several mechanisms are involved in immune regulation and response to stress stimuli, including RT.

\section{RT INCREASES TYPE I IFN SECRETION VIA STING ACTIVATION: A DICHOTOMY BETWEEN DENDRITIC CELL AND MDSC RECRUITMENT DETERMINES THE THERAPEUTIC RESPONSE TO RADIATION}

When RT induces tumor cell death, DNA from dying tumor cells is delivered to antigen presenting cells (APCs), most notably 
CD11c+ dendritic cells (DCs). In this process DCs are stimulated to present antigens, and express costimulatory molecules (28). A critical mediator of DC function is the stimulator of interferon genes (STING). STING pathway activation (Figure 2) occurs when DNA from tumor cells taken up by APCs is sensed by cyclic-GMP-AMP (cGAMP) synthase, which interacts directly with STING to induce a conformational change leading to translocation of STING from the endoplasmic reticulum to perinuclear vesicles (29). Inside the nucleus, STING recruits and phosphorylates TANK-binding kinase 1 (TBK1), which activates interferon regulatry factor 3 (IRF3). Finally, IRF3 induces expression of Type I IFNs (30). Type I IFN release from APCs facilitates the ability of Batf3 DCs to take up antigen (31). This stimulates maturation of DCs and cross-presentation of tumor associated antigens (TAA) to $\mathrm{CD} 8^{+} \mathrm{T}$ cells, which mediate antitumor immunity after proliferation and infiltration into the tumor microenvironment.

Type I IFNs induced by RT include IFN $-\alpha,-\beta$ and the less studied IFN $\tau,-\varepsilon,-\kappa$, and $-\omega$. Expression of Type I IFN and Type I-inducible genes is associated with $\mathrm{T}$ cell-infiltrated tumors $(32,33)$. In addition, Type I IFN expression can be induced by RT. Burnette et al. showed increased Type I IFNs in a melanoma cancer model (B16-SYI) after 20 Gy of local RT (34). Knockdown of IFN- $\beta$ receptor (IFN- $\alpha$ receptor 1 ) in B6/IFNAR1 KO mice abolished RT's ability to reduce tumor growth in this model. Lim et al. showed similar findings with a dose of $15 \mathrm{~Gy}$ (35). These data suggest that Type I IFNs, specifically IFN- $\beta$, may be key targets by which RT modulates the TME.

Deng et al showed that innate immune sensing following RT is predominantly mediated by a STING-dependent mechanism (31). The study demonstrated that cGAS- and STINGdependent cytosolic DNA sensing in DCs is required for type I IFN induction after RT and that adding the STING agonist cGAMP reduces radioresistance and enhances antitumor

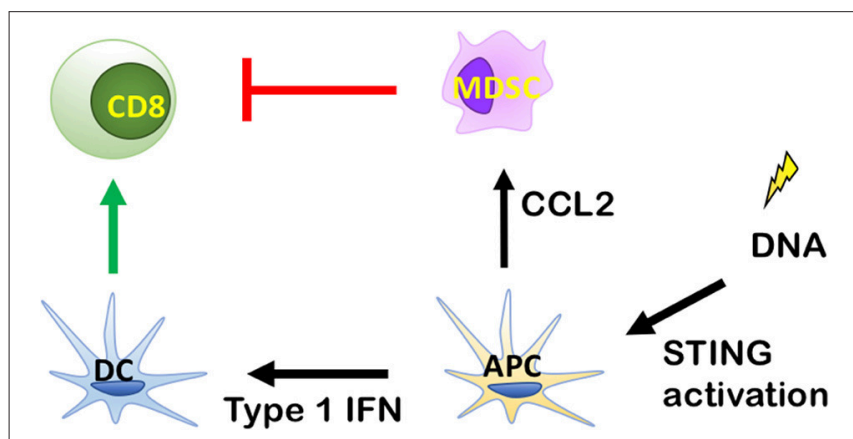

FIGURE 2 | Role of the stimulator of interferon genes (STING) signaling pathway in antitumor immunity. By inducing Type I IFN release from antigen presenting cells (APCs), radiation therapy (RT) can enhance antigen uptake by specialized dendritic cells (DCs) known as Batf3 DCs. This stimulates maturation of DCs and the cross-presentation of tumor associated antigens (TAA) to $\mathrm{CD}^{+}{ }^{+}$T cells, which exhibit antitumor immunity after proliferation and infiltration into tumor microenvironment. DNA from tumor cells is recognized by cytosolic DNA sensor cGAS to produce cGAMP for STING activation and cytokine production, which stimulate the maturation of DCs and stimulate the cross-presentation of TAA to $\mathrm{CD}^{+}{ }^{+} \mathrm{T}$ cells, which exhibit antitumor immunity after proliferation and infiltration into the tumor microenvironment. immune responses. However, the paradox of RT-mediated STING activation is that it can also recruit MDSCs $(34,36)$. While this could be an RT dose-dependent phenomenon, the recruitment of MDSCs by RT can inhibit $\mathrm{CD} 8^{+} \mathrm{T}$ cells and DC activity, thus negating any benefit from activation of the Type I IFN pathway. This has been demonstrated in MC38 colon tumors where irradiation was shown to primarily increase monocytic MDSCs (Ly6c ${ }^{\text {hi }}$ CD11b+ cells) (36). In support of this being mediated via the STING pathway, tumor irradiation in STING KO mice led to a significant decrease in MDSC recruitment (36). This evidence supports STING as an initiating factor in MDSC recruitment. It is possible that STING-mediated RT effects are tumor-specific. Tumors that are poorly MDSC infiltrated and/or do not induce MDSC chemoattractants in response to RT may benefit from a STING agonist in combination with RT. In contrast, tumors that are MDSC rich and/or activate MDSC recruitment in response to RT may require strategies for targeting MDSCs. Combining MDSC targeting therapies with RT may not only enhance STING activation, but also increase Type I IFN production and recruitment of $\mathrm{CD} 8^{+}$ $\mathrm{T}$ cells $(37,38)$.

A potential target through which RT increases MDSC recruitment is the monocyte chemoattractant CCL2. In the MC38 colon tumor model above, genetic knockdown of CCL2 yielded complete tumor eradication in $60 \%$ of irradiated mice further supporting MDSCs as a major driver of immunosuppression (36). Similarly, monoclonal antibodies against CCL2 led to tumor rejection in $40 \%$ of mice, but only when combined with RT (36). Anti-CCL2 antibody therapy combined with RT also resulted in an increase of $\mathrm{CD} 8^{+} \mathrm{T}$ cell activity, measured by INF- $\gamma$ by Elispot assay (36). Antitumor immune-mediated effects of CCL2 genetic knockdown or anti-CCL2 antibody treatment were abolished when both $\mathrm{CD}^{+}{ }^{+}$and $\mathrm{CD} 4^{+} \mathrm{T}$ cells were depleted (36). This evidence indicates that MDSCs block RT-induced T-cell antitumor activity via CCL2 and suggests this is a therapeutic target that could be manipulated to tip the balance in favor of dendritic cell recruitment.

Combining MDSC targeting therapies with RT may not only enhance STING activation, but also increase Type I IFN production and recruitment of $\mathrm{CD} 8^{+} \mathrm{T}$ cells $(37,38)$. For tumors where MDSCs play a prominent role, using RT with STING immunotherapies may not be sufficient. MDSCs may be able to block the positive effects of these therapies by inhibiting $\mathrm{CD} 8^{+}$ $\mathrm{T}$ cell activity. For these tumors, adding anti-CCL2 antibodies to the treatment may be prudent.

In addition to MDSCs, M2 macrophages play a similar role in mediating immune suppression and resistance to RT (39). The IL-6/JAK/STAT3 pathway has been shown to polarize macrophages toward the pro-tumoral M2 phenotype through activation of STAT3, and anti-IL-6 immunotherapy increased the number of M1 polarized macrophages in a hepatocellular carcinoma mouse model (40). A review focused on the IL6/JAK/STAT3 pathway, its role in cancer, and possible inhibitors of the pathway was recently published by Johnson et al. (41). The effects of targeting IL- 6 with RT in a murine model of prostate cancer resulted in attenuation of angiogenesis, MDSC recruitment and decreased tumor growth (39). 
Collectively, these studies highlight that it may be prudent to combine RT with immunotherapies that target MDSC and/or M2 macrophage recruitment and polarization to enhance antitumor immune responses. Some initial successes in targeting macrophages have been achieved. Anti-CSF1 immunotherapy, when used in combination with RT, prolonged survival in a glioblastoma (GBM) mouse model and significantly reduced RT-mediated macrophage recruitment to the tumor (42). Chloroquine, a common drug used to treat malaria, has also been shown to have anti-tumor effects via its ability to convert M2s into an M1 phenotype. Alone, chloroquine was able to reduce tumor burden in a murine melanoma and a hepatocarcinoma model (43). Since chloroquine was shown to be dependent on $\mathrm{T}$ cells for its effects (43), it might induce an even larger reduction in tumor burden when combined with RT given RT's potent effect on increasing T cell infiltration. Finally, myeloid cells' activation status can be targeted for therapeutic development. One such example is CD40 a surface protein present on most APCs (44). When CD40 is activated on APCs by binding to CD40L, APCs are able to present antigens to T cells (45). Increasing antigen presentation with anti-CD40 therapy in combination with $\mathrm{RT}$ was shown to increase survival of a B-cell lymphoma mouse model to $100 \%$ when the study ended at 100 days post-tumorinoculation (46).

\section{PD-L1-DEPENDENT RESISTANCE AND PD-L1-INDEPENDENT RESISTANCE: HOW $\mathrm{CD}^{+}{ }^{+} \mathrm{T}$ CELLS NEGATIVELY REGULATE THEIR OWN ACTIVATION BY IFN- $\gamma$ AND CCL22 SECRETION}

RT's ability to recruit and activate $\mathrm{CD}^{+} \mathrm{T}$ cells by inducing secretion of chemoattractant molecules CXCL9, CXCL10, CXCL16, and CCL5 as a response to tissue damage is well-known (47-52). Despite this, resistance to RT still occurs. This is in part explained by $\mathrm{CD} 8^{+} \mathrm{T}$ cell exhaustion, which is characterized by increased expression of immune checkpoint receptors such as PD-1, resulting in PD-L1-dependent resistance (53). Tumorintrinsic factors can determine the extent of PD-L1 expression in tumors treated with RT and chemotherapeutic agents (27), but it also increases in response to IFN- $\gamma$ (53). Gajewski et al. found evidence that activated $\mathrm{CD}^{+} \mathrm{T}$ cells and their secretion of IFN- $\gamma$ are responsible for promoting PD-L1 expression in the TME in a negative feedback loop in vivo (36). IFN- $\gamma$ has been known for supporting an anti-tumor TME by promoting Th1 polarization, cytotoxic $\mathrm{T}$ cell activation, DC maturation (54), and increased CXCL9 secretion (55). But evidence now suggests that IFN- $\gamma$ can also upregulate PD-L1 in the TME (53) (Figure 3).

IFN- $\gamma$ 's upregulation of PD-L1 has been shown in both murine and human tumor cell lines (56). The presence of both high $\mathrm{CD} 8^{+} \mathrm{T}$ cell infiltration and IFN- $\gamma$ is required for PD-L1's increase in tumors. This has been demonstrated by comparing levels of PD-L1 and IFN- $\gamma$ in WT mice and CD8 KO mice in multiple murine melanoma models (53). It has been postulated that IFN- $\gamma$ upregulates PD-L1 expression through activation

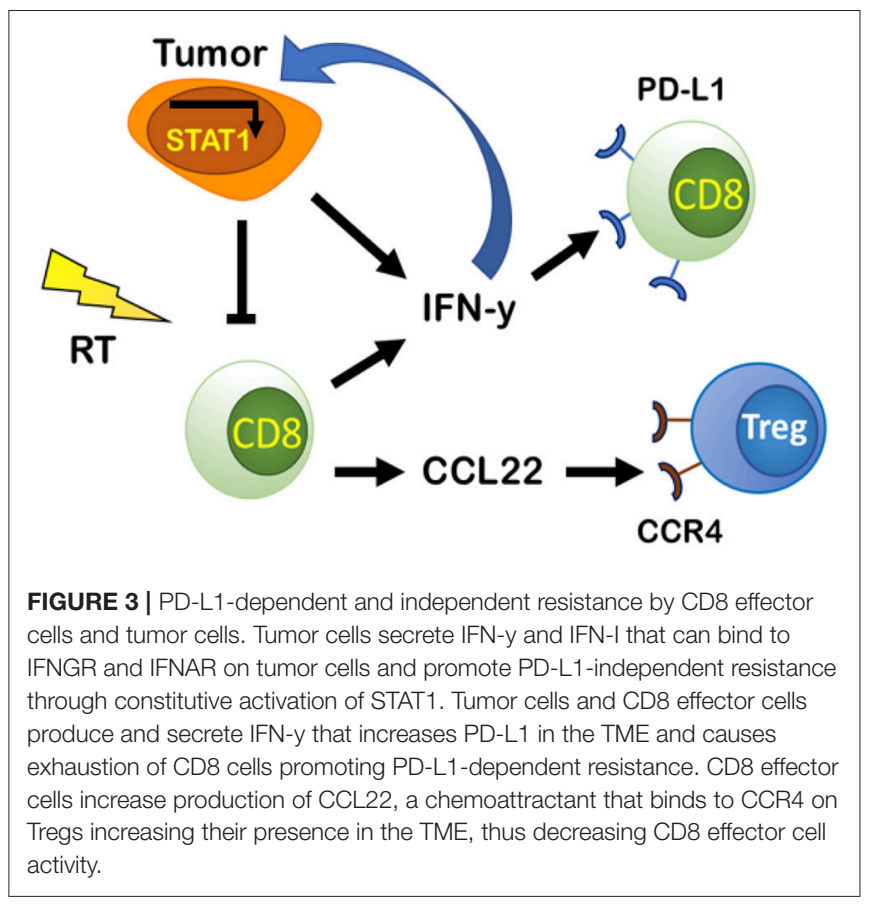

of IRF-1, an interferon regulatory factor with a binding site on the promotor of the gene coding for PD-L1 (57). IFN$\gamma$ 's upregulation of PD-L1 supports the rationale for anti-PDL1/PD-1 axis therapies in cancer therapy, but it also highlights why these therapies are only useful for a small portion of patients with high baseline levels of PD-L1 expression. Many tumors are devoid of $\mathrm{T}$ cells at baseline, and thus lack PD-L1 expression or effector T cells (Teff cells) that can be activated by anti-PD1/PD-L1 therapies (58). Combining such therapies with RT could be beneficial as RT increases PD-L1 expression and enhances infiltration of Teff cells (59).

Although combining RT and PD-L1 therapy has improved outcomes in more patients than anti-PD-L1 treatment alone, emerging data suggest that resistance still develops (24). In preclinical models, Benci et al. identified a novel role for INF- $\gamma$ and Type I IFNs in PD-L1-independent resistance and showed that targeting IFN- $\gamma /$ Type I IFNs resulted in decreasing $\mathrm{T}$ cell exhaustion (60). To determine if IFN- $\gamma$ was responsible for resistance independent of PD-L1 expression, PD-L1 was deleted in tumor cells using CRISPR and PD-L1 was deleted in tumor associated macrophages (TAMs) or globally deleted with antiPD-L1 therapy. The authors reported that IFN- $\gamma$ expression was still able to induce resistance when PD-L1 was deleted, but when IFN- $\gamma$ 's receptor IFNGR and the receptor for Type I IFNs IFNAR were knocked out on tumor cells, exhausted T cells were significantly reduced and response to RT and anti-CTLA4 was enhanced (60). These data demonstrate that IFN- $\gamma$ and Type I IFNs are responsible for promoting resistance to combined RT and anti-CTLA-4 treatment in a PD-L1-independent manner (60). Benci et al. further showed that this resistance is mediated by constitutive activation of STAT1 expression in tumor cells through genomic studies and effect studies involving STAT1 KOs combined with anti-PD-L1 treatment (60). Based on these 
results and the finding that IFN-stimulated genes are increased in patients who develop resistance to anti-PD-L1 therapy (60), screening patients for IFN-stimulated genes may determine if patients qualify for therapeutic combinations of RT, anti-PD-L1, or anti-IFN therapy.

$\mathrm{CD}^{+} \mathrm{T}$ cells can also regulate their own activity by recruiting Tregs through the CCL22-CCR4 axis (Figure 3). Gajewski et al. demonstrated that an increase in CCR4-expressing Tregs as a percentage of total immune cells was observed only when $\mathrm{CD} 8^{+}$ $\mathrm{T}$ cells were present (53). In CD8 KO mice, Tregs represented a lower percentage of total immune cells (53). Through a series of experiments, they showed that secretion of CCL22 by CD ${ }^{+}$ $\mathrm{T}$ cells recruits $\mathrm{T}$ cells and supports their proliferation without inducing $\mathrm{T}$ cell differentiation (53). Additionally, inhibition of CCR4 using the antagonist C021 prevented Treg accumulation in tumors (53). Targeting CCR4 could be a promising therapeutic target, especially in Treg enriched tumors. Such a therapy may have enhanced efficacy when combined with RT to induce Teff cell infiltration.

\section{RT-INDUCED ADENOSINE: SHIFTING THE TME FROM DENDRITIC CELL RECRUITMENT TOWARD TREG- AND M2- MEDIATED IMMUNE SUPPRESSION}

Immunogenic cell death resulting from tumor irradiation alerts the immune system to a potential threat via upregulation or release of DAMPs, including adenosine triphosphate (ATP). The dose-dependent release of ATP as a result of RT-induced cancer cell death (61), can recruit and activate DCs to uptake tumor antigens and cross-present them to naïve $\mathrm{T}$ cells, thus initiating antitumor immune responses (62) (Figure 4). However, ATP is rapidly catabolized into adenosine in the TME by the ectoenzymes CD39 and CD73 expressed on tumor cells, stromal cells, and immune cells, primarily, Tregs and Th17 cells. CD39 hydrolyzes ATP to ADP, and ADP into AMP, and then CD73 converts AMP into adenosine (63). Local accumulation of extracellular adenosine suppresses DCs and Teff cells while promoting proliferation of Tregs, increases the expression of CTLA-4 and adenosine receptor 2A (A2AR) on Tregs, and enhanced the polarization of tumor-associated macrophages (TAMs) into an M2 suppressive phenotype $(64,65)$.

Conversion of ATP to adenosine can be induced directly by RT. One mechanism for this conversion is mediated via the induction of reactive oxygen species (ROS) by RT, which then converts pro-TGF- $\beta$ into its activated form (66). TGF- $\beta$ promotes TAM polarization into M2s and upon glucocorticoid induction, TGF- $\beta$ modifies gene expression in M2 macrophages to express additional immune-suppressive genes like the one coding for IL17 receptor (IL17RB) that promotes development of Th17 cells. TGF- $\beta$ is also able to increase the expression of ectonucleotidases CD73 and CD39 on Th17 cells by downregulating zinc finger protein growth factor independent-1 (Gfi-1) and by inducing Stat3 expression, respectively (67). Taken together, TGF- $\beta$

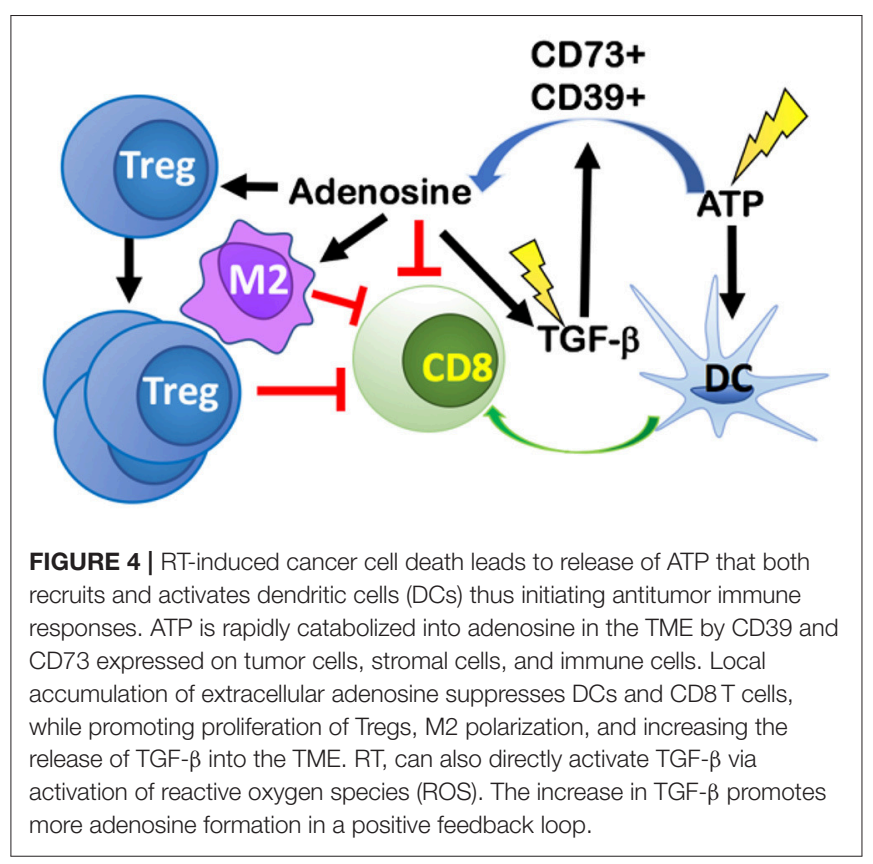

increases the number of Th17 cells and the expression of genes responsible for converting ATP into adenosine in Th17 cells.

Therapeutic targeting of A2AR, CD73, and TGF- $\beta$ may shift the TME to a pro-ATP environment and reduce resistance to immunotherapy in the setting of RT. In preclinical animal models, targeting A2AR, the receptor for adenosine, with a pharmacological inhibitor SCH58261 led to a significant decrease in tumor growth and reduced Tregs while enhancing Teff cell activity in a spontaneous Cre/lox HNSCC model (68). Targeting A2AR alone with CPI-444 led to a significant reduction in tumor burden for mice implanted with MC38 tumors (69). Further tumor regression was achieved by the addition of antiPD-L1 and anti-CTLA-4 treatment in both MC38 and CT26 tumors. The combination of CPI-444 and anti-PD-L1 in MC38 implanted mice led to a $50 \%$ eradication of the tumors $(5 / 10)$ (69). Another way to reduce the effects of adenosine is to limit its production in the first place by targeting CD73. Targeting CD73 with an anti-CD73 monoclonal antibody (mAb), antiCD73 decreased the tumor burden and increased the survival of mice with MC38-OVA tumor cells (70). This effect was even greater when combined with anti-PD-L1 and anti-CTLA4 (70). Another group found that CD73 knockout mice had greater homing of Teff cells and that this effect was primarily driven by CD73 expression on Tregs (71). Although blocking production and direct action of adenosine has been shown to be effective, therapeutic strategies aimed at targeting TGF- $\beta$ can be of more significant benefit in combination with RT. TGF$\beta$ increases the expression of both CD73 and CD39 and is responsible for promoting a variety of pro-tumor effects. There has been some hesitation in targeting TGF- $\beta$ in the past because of the potential for cardiac toxicities, but new-generation smallmolecule inhibitors have been shown to have limited side effects in clinical trials (72-74). The newly developed bifunctional fusion protein, M7824, TGF- $\beta$ Trap (75) is another potential therapeutic 
target to combine with RT, as it simultaneously blocks the PDL1 and TGF- $\beta$ pathways and might yield increased response compared to monotherapy alone.

\section{CLASSIC RT ANTI-TUMOR EFFECTS MEDIATED THROUGH ROS HAVE A DARK SIDE: INCREASING ADENOSINE THROUGH TREG APOPTOSIS AND CREATING A HYPOXIC IMMUNOSUPPRESSIVE TME}

RT is classically known to act on cancer cells by inducing apoptosis, senescence, and mitotic catastrophe through the production of reactive oxygen species (ROS) that, at high enough concentrations, can damage cells and cause double-stranded DNA damage $(2,3)$. It was thought that these effects would primarily affect tumor cells, causing tumor cell death, and-based on current understanding-increase tumor associated antigens for immune cell recognition. Recently, Zou et al. showed that within the immune TME, ROS resulting from RT induced apoptosis of Tregs driving increased immunosuppression. Their data support a hypothesis that apoptotic, but not proliferating, Tregs release high levels of ATP and subsequently metabolize ATP into adenosine because CD73 and CD39 are still metabolically active (76) (Figure 5). This fundamentally changes the current dogma of targeting all Tregs with immunotherapies. If Treg apoptosis is driving immunosuppression, an ideal immunotherapy would decrease Treg activity and proliferation, without inducing their apoptosis.

A more hypoxic environment will be less sensitive to the effects of RT (77), and many solid tumors are known to be more radioresistant in hypoxic regions. Although there is intrinsic hypoxia due to the nature of solid tumors, RT can worsen hypoxic conditions by increasing hypoxia-inducible factor- $1 \alpha$

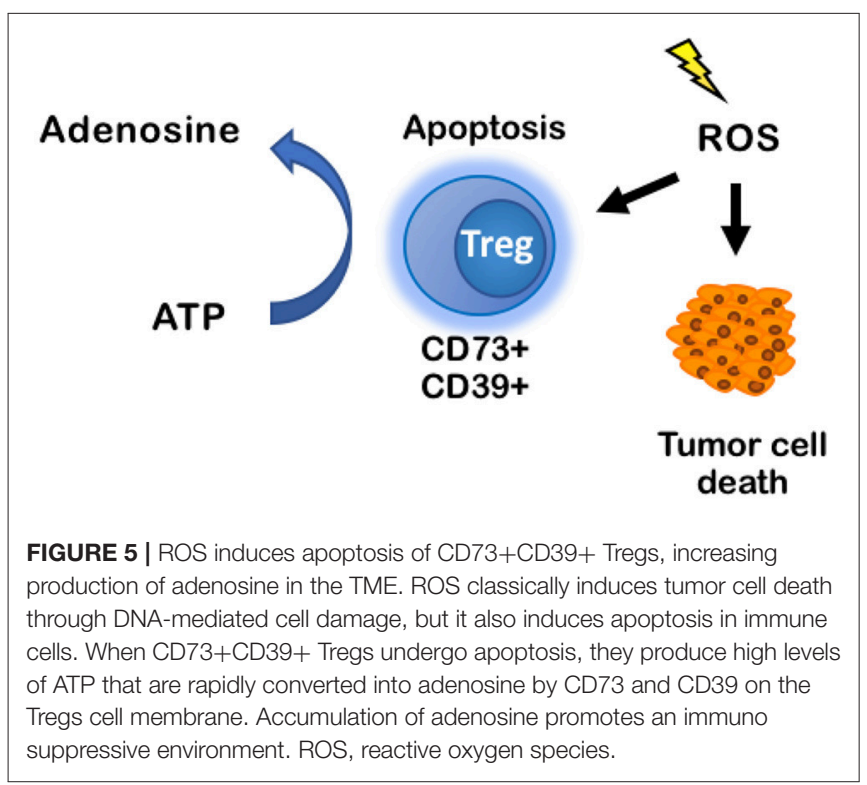

(HIF-1 $\alpha$ ). HIF- $1 \alpha$ has been shown to cause radioresistance of endothelial cells (78), angiogenesis through expression of vascular endothelial growth factor A (VEGF-A) (79), malignant progression (79), and poor survival outcomes after RT treatment $(80,81)$. Upregulation of HIF- $1 \alpha$ by RT can be a direct result of stabilizing HIF- $1 \alpha$ in cancer cells $(78,79)$, or it can occur indirectly as RT increases TAMs, which also stabilize HIF-1 $\alpha$ (82).

Within the TME, HIF-1 $\alpha$ mediates immunosuppression by modulating specific immune cell functions (Figure 6). It modulates gene expression and cytokine production in MDSCs, thereby increasing their role in $\mathrm{T}$ cell suppression. HIF- $1 \alpha$ inhibits myeloid cell differentiation through a VEGF-A mediated mechanism leading to accumulation of $\operatorname{MDSCs}(83,84)$. Induced by RT, VEGF-A can also increase inhibitory receptors on $\mathrm{CD}^{+} \mathrm{T}$ cells (e.g., Tim-3, CTLA-4, PD-1, Lag-3) (85) as well as PDL-1 expression on tumor cells and MDSCs (86), thereby promoting $\mathrm{T}$ cell exhaustion and inactivity (85). Another mechanism by which RT-induced VEGF-A secretion can enhance a pro-tumor environment is through its influence on endothelial cells by inducing expression of CD95L (or FasL), the ligand for FAS $(87,88)$. In response to RT, expression of Fas can be induced by tumor cells secreting IL-10, prostaglandin E2, and VEGF-A (89). Fas can induce apoptosis of Teff cells, while sparing Tregs to support an anti-tumor environment (90).

HIF-1 $\alpha$ represents an ideal target for reducing the immunosuppression driven by a hypoxic environment, but




currently no drugs are approved for clinical trials in humans. Drugs designed in an attempt to target HIF-1 $\alpha$ have had many off-target effects, including but not limited to inhibiting mRNA expression, protein synthesis, protein degradation, and DNA binding (91). In the future, more effective and specific inhibitors of HIF-1 $\alpha$ will be developed. In the meantime, targeting VEGF-A may have some potential. There are several FDA-approved drugs that target VEGF-A, including the monoclonal antibody bevacizumab (66). Pre-clinical and clinical applications of these drugs have been well-described by others recently (92-94). Briefly, inhibiting VEGF-A appears to produce only a modest increase in survival for patients with a wide range of tumor types (95-99). These modest effects could be the result of indiscriminate administration of the drugs and/or parallel pathways of resistance. Combination approaches targeting both VEGF-A and HIF-1 $\alpha$ axes or with cox-1 inhibitors as described in the next section could prove to be more beneficial than any single approach.

\section{RT'S REMODELING OF THE EXTRACELLULAR MATRIX AND ENDOTHELIAL CELLS: PROMOTING FIBROSIS, MMP ACTIVITY, AND FASL EXPRESSION}

By increasing the number and activity of fibroblasts and MMPs, and increasing pro-tumoral endothelial cell function, RT can directly modulate the extra-cellular matrix (ECM) component of the TME (Figure 7). RT-mediated TGF- $\beta$ signaling increases the number of cancer-associated fibroblasts (CAFs) or myofibroblasts in the ECM. These cells deposit type I, type II, type III, and type V collagen, fibronectin, and matrix metalloproteinases (MMPs) that regulate ECM homeostasis (100-102). CAFs also express fibroblast activation protein (FAP) (103) enhancing immunosuppression within the TME via CXCL12 (104), a chemokine that reportedly coats tumor cells and inhibits recruitment of T cells in the area (104) and reduces ECM-associated fibrosis (105).

RT can directly modulate endothelial cell function to inhibit Teff cell immune function and create a pro-tumoral TME. Upregulation of FasL, on endothelial cells has been shown to be a critical mediator of Teff cell inhibition in a variety of cancers $(87,88,90)$. Fas can induce preferential apoptosis in Teff, while sparing CD25-expressing Tregs, favoring an immunosuppressive TME (90). Tumor-derived IL-10 and prostaglandin E2 can independently increase endothelial cell expression of Fas, and tumor derived VEGF-A is dependent on the presence of IL10 or prostaglandin E2 to further increase Fas expression (90). This explains why a blockade of FasL expression in different ovarian cancer cell lines by targeting VEGF-A was shown to be drastically enhanced when combined with COX1 inhibitors (90). VEGFA's effects were dependent on the amount of COX 1 expression, implying that VEGF-A is necessary but not always sufficient to produce FasL (90). These results have been corroborated by findings in four distinct murine cancer models: ovarian, skin, colon, and renal cancer (90). Treatment of these tumors with

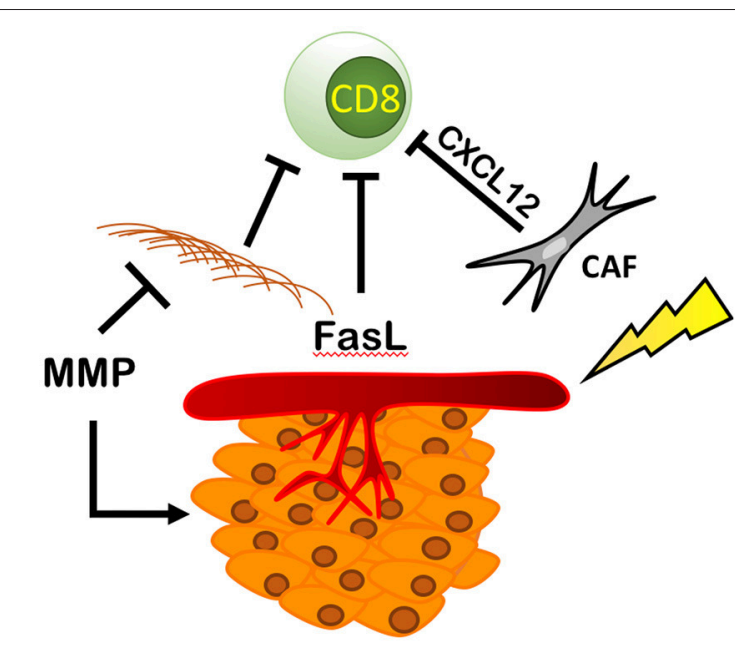

FIGURE 7|RT modulates fibroblasts, ECM, and endothelial cells resulting in an immunosuppressive environment. RT increases the number and activity of cancer associated fibroblasts (CAFs) increasing the production of CXCL12, blocking $\mathrm{CD} 8^{+} \mathrm{T}$ cell recruitment and increasing the amount of $\mathrm{ECM}$ proteins produced by fibroblasts physically blocking immune cells from entering the TME. This is countered by RT's ability to increase the expression of MMPs that break down the ECM, increasing cancer spread and metastasis. Finally, RT is able to increase the expression of Delta, Jagged, Notch, and FasL, thus reducing $C D 8^{+} \mathrm{T}$ cell recruitment and promoting tumor growth and survival.

anti-VEGF-A combined with a COX 1 inhibitor, salicylic acid, resulted in depletion of FasL expression on tumor endothelial cells, an increase in $\mathrm{CD}^{+} \mathrm{T}$ cells infiltrating the TME, and a reduction in tumor growth (90). Targeting VEGF-A alone has had modest effects on overall survival in clinical trials (92-94). Of note, aspirin has also been associated with prevention of colorectal cancer and a reduction in colorectal cancer mortality (106). Combining VEGF-A inhibitors with daily aspirin use may present a potential therapeutic combination to improve upon these modest anti-VEGF-A effects.

RT can also modulate the vascular TME to enhance tumor metastasis, which is in part mediated by upregulation of various genes involved in migration/metastasis. Tumor cell dissemination via blood vessels requires tumor cells to undergo transendothelial migration. This occurs at sites where leukocytes and macrophages are in direct contact with tumor cells and endothelial cells. The best studied proteins at these sites are Jagged, Delta, and Notch (107). Activated Notch1 has been shown to inhibit apoptosis and enhance radioresistance (108), while downregulation of Notch1 expression can induce radiosensitization and alleviate radiation-induced epithelialmesenchymal transition (EMT) (109-111). Activation of the Notch signaling pathway upregulates E-selectin expression on endothelial cells that shields tumor cells in the blood stream from anoikis (112). In breast cancer models, inhibition of the Notch signaling pathway blocked macrophage-induced intravasation in vitro and the dissemination of tumor cells from the primary tumor in vivo (113). The association between EMT and radioresistance and the prominent role of Notch signaling as a 
driving force in the EMT process, suggest that Notch inhibition will result in radiosensitization of tumors that underwent EMT.

Targeting the fibrotic TME can be challenging. Kalluri et al. found that when myofibroblasts were eliminated from the TME using transgenic mice, cancer progression and outcome were worse (113). Deletion of myofibroblasts was also associated with a reduced Teff/Treg ratio and elevated CTLA-4 expression (113). This could be because certain structure is needed to allow for normal functioning of immune cells and to keep the tumor in place. However, some tumor types are known to be highly fibrotic, hence reducing, but not eliminating, fibrosis may be important for enhancing anti-tumor immunity. As treatment with RT can result in a significant increase in fibrosis in these tumors (114-118), it may also be important to use anti-fibrotic agents to reduce fibrosis to pre-RT levels. Some available drugs are being tried pre-clinically to reduce fibrosis. For example, Pirfenidone, which inhibits TGF-induced fibrosis by targeting the TGF- $\beta 1 /$ Smad/CTGF pathway (119) has been shown to reduce RT-mediated fibrosis in a murine lung carcinoma model (120) and increase survival (121). Another avenue to increase $\mathrm{T}$ cell infiltration is targeting CXCL12 or its receptor, CXCR4. Targeting both has been shown to reduce RTassociated lung fibrosis (122), and anti-CXCL12 therapy alone increases T cell infiltration into tumors (104). Although directly targeting $\mathrm{FAP}+$ cells represents an attractive therapeutic strategy, thus far targeting FAP alone has shown no benefit in clinical trials (115).

\section{CONCLUSION}

There is now considerable evidence that single-agent immune therapies have limited response in various cancer sites (123126). Radiation therapy has been shown to synergize with immune modulating therapy through several mechanisms including exposure of neo-antigens, STING activation and PDL1 upregulation $(31,59,127)$. In addition to synergy where each component contributes to tumor response, radiation therapy can transform tumors and sensitize them to immune therapies $(7,9,12,17)$. However, in both cases the response to combination RT and immune therapy can be transient. The challenge ahead is to determine why the combination of RT and immune therapy provides a durable response in some patients and a limited response in others. Specifically, future studies should focus on identification of how RT's

\section{REFERENCES}

1. Delaney G, Jacob S, Featherstone $C$, and Barton $M$. The role of radiotherapy in cancer treatment: estimating optimal utilization from a review of evidence-based clinical guidelines. Cancer (2005) 104:1129-37. doi: 10.1002/cncr. 21324

2. Sharabi AB, Lim M, DeWeese TL, Drake CG. Radiation and checkpoint blockade immunotherapy: radiosensitisation and potential mechanisms of synergy. Lancet Oncol. (2015) 16:e498-509. doi: 10.1016/S1470-2045(15)00007-8 paradoxical effects manifest in responders and non-responders. The response to RT and immune modulating therapy can be suppressed through additional mechanisms of immune-evasion and immune-suppression including chronic IFN- $\gamma$ activation, conversion of ATP to adenosine, ECM remodeling and secretion of immunosuppressive factors that promote infiltration of Tregs, MDSCs and macrophages. These mechanisms are likely activated by tumor-intrinsic factors that should be identified and targeted to develop effective therapies. It is conceivable that such factors will affect RT response differently between patients with the same cancer type and across different cancer types. Therefore, identifying diagnostic biomarkers for these factors is an important next step. Tumor staining for PDL1 expression has been successfully implemented in NSCLC and melanoma patients to identify candidates who will benefit from anti-PD-1/anti-PD-L1 therapy. Additional markers are warranted to identify candidates such as immune checkpoint receptors such as TIM-3, LAG-3, CTLA-4, as well as assessment of intratumoral Tregs, MSDCs and macrophages are warranted. Furthermore, assessment of secreted factors will be important for identifying patients who can benefit from therapies that target recruitment and homing of immune suppressive cell populations. Such factors include TGF- $\beta$, ATP, CCL2, CCL20, and CCL22. Another challenge of integrating RT with immunotherapy is identifying the RT dose and fractionation resulting in optimal synergy. Most evidence suggests that hypofractionated RT is better suited for integration with immunotherapy, but there is also evidence that conventional fractionation can achieve similar results. Consideration for when certain immune cell populations are more abundant may be beneficial in determining an optimal dosing schedule $(128,129)$. It is important to design clinical trials that address RT's effects on the TME, as well as dosing and fractionation when combined with immunotherapy. Selecting rational combinations of therapies based on both forward and reverse translation, rigorous preclinical studies, and careful analysis of trial specimens is needed to generate a mechanistic understanding of the effects of treatment on the tumor and the associated microenvironment.

\section{AUTHOR CONTRIBUTIONS}

LD, AO, and SDK contributed to the writing and editing of the manuscript. SDK is responsible for supervision of this work.
3. Eriksson D, Stigbrand T. Radiation-induced cell death mechanisms. Tumour Biol. (2010) 31:363-72. doi: 10.1007/s13277-010-0042-8

4. Bernstein MB, Krishnan S, Hodge JW, Chang JY. Immunotherapy and stereotactic ablative radiotherapy (ISABR): a curative approach? Nat Rev Clin Oncol. (2016) 13:516-24. doi: 10.1038/nrclinonc.2016.30

5. Chajon E, Castelli J, Marsiglia H, De Crevoisier R. The synergistic effect of radiotherapy and immunotherapy: a promising but not simple partnership. Crit Rev Oncol Hematol. (2017) 111:124-32. doi: 10.1016/j.critrevonc.2017.01.017

6. Frey B, Rubner Y, Wunderlich R, Weiss EM, Pockley AG, Fietkau R, et al. Induction of abscopal anti-tumor immunity and immunogenic tumor cell 
death by ionizing irradiation - implications for cancer therapies. Curr Med Chem. (2012) 19:1751-64. doi: 10.2174/092986712800099811

7. Demaria S, Kawashima N, Yang AM, Devitt ML, Babb JS, Allison JP, et al. Immune-mediated inhibition of metastases after treatment with local radiation and CTLA-4 blockade in a mouse model of breast cancer. Clin Cancer Res. (2005) 11:728-34.

8. Dewan MZ, Galloway AE, Kawashima N, Dewyngaert JK, Babb JS, Formenti SC, et al. Fractionated but not single-dose radiotherapy induces an immunemediated abscopal effect when combined with anti-CTLA-4 antibody. Clin Cancer Res. (2009) 15:5379-88. doi: 10.1158/1078-0432.CCR-09-0265

9. Yoshimoto Y, Suzuki Y, Mimura K, Ando K, Oike T, Sato H, et al. Radiotherapy-induced anti-tumor immunity contributes to the therapeutic efficacy of irradiation and can be augmented by CTLA- 4 blockade in a mouse model. PLoS ONE (2014) 9:e92572. doi: 10.1371/journal.pone.0092572

10. Belcaid Z, Phallen JA, Zeng J, See AP, Mathios D, Gottschalk C, et al. Focal radiation therapy combined with $4-1 \mathrm{BB}$ activation and CTLA4 blockade yields long-term survival and a protective antigen-specific memory response in a murine glioma model. PLoS ONE (2014) 9:e101764. doi: 10.1371/journal.pone.0101764

11. Sharabi AB, Nirschl CJ, Kochel CM, Nirschl TR, Francica BJ, Velarde E, et al. Stereotactic radiation therapy augments antigen-specific PD-1-mediated antitumor immune responses via cross-presentation of tumor antigen. Cancer Immunol Res. (2015) 3:345-55. doi: 10.1158/2326-6066.CIR-14-0196

12. Zeng J, See AP, Phallen J, Jackson CM, Belcaid Z, Ruzevick J, et al. Anti-PD1 blockade and stereotactic radiation produce long-term survival in mice with intracranial gliomas. Int J Radiat Oncol Biol Phys. (2013) 86:343-9. doi: 10.1016/j.ijrobp.2012.12.025

13. Shaverdian N, Lisberg AE, Bornazyan K, Veruttipong D, Goldman JW, Formenti SC, et al. Previous radiotherapy and the clinical activity and toxicity of pembrolizumab in the treatment of non-small-cell lung cancer: a secondary analysis of the KEYNOTE-001 phase 1 trial. Lancet Oncol. (2017) 18:895-903. doi: 10.1016/S1470-2045(17)30380-7

14. Dovedi SJ, Adlard AL, Lipowska-Bhalla G, McKenna C, Jones S, Cheadle EJ, et al. Acquired resistance to fractionated radiotherapy can be overcome by concurrent PD-L1 blockade. Cancer Res. (2014) 74:5458-68. doi: 10.1158/0008-5472.CAN-14-1258

15. Deng L, Liang H, Burnette B, Beckett M, Darga T, Weichselbaum RR, et al. Irradiation and anti-PD-L1 treatment synergistically promote antitumor immunity in mice. J Clin Invest. (2014) 124:687-95. doi: 10.1172/JCI67313

16. Zheng W, Skowron KB, Namm JP, Burnette B, Fernandez C, Arina $A$, et al. Combination of radiotherapy and vaccination overcomes checkpoint blockade resistance. Oncotarget (2016) 7:43039-51. doi: 10.18632/oncotarget.9915

17. Schaue D, Ratikan JA, Iwamoto KS, McBride WH. Maximizing tumor immunity with fractionated radiation. Int J Radiat Oncol Biol Phys. (2012) 83:1306-10. doi: 10.1016/j.ijrobp.2011.09.049

18. Wang Y, Deng W, Li N, Neri S, Sharma A, Jiang W, et al. Combining immunotherapy and radiotherapy for cancer treatment: current challenges and future directions. Front Pharmacol. (2018) 9:185. doi: 10.3389/fphar.2018.00185

19. Gandhi SJ, Minn AJ, Vonderheide RH, Wherry EJ, Hahn SM, Maity A. Awakening the immune system with radiation: optimal dose and fractionation. Cancer Lett. (2015) 368:185-90. doi: 10.1016/j.canlet.2015.03.024

20. Monjazeb AM, Schoenfeld JD. Radiation dose and checkpoint blockade immunotherapy: unanswered questions. Lancet Oncol. (2016) 17:e3-4. doi: 10.1016/S1470-2045(15)00541-0

21. Weichselbaum RR, Liang H, Deng L, Fu YX. Radiotherapy and immunotherapy: a beneficial liaison? Nat Rev Clin Oncol. (2017) 14:365-79. doi: $10.1038 /$ nrclinonc.2016.211

22. Cherry RC, Hegde AM, Stroud CRG, Pinnamaneni R, Cherukuri SD, Sharma N, et al. Outcomes of immunomodulatory radiation strategies in combination with nivolumab compared with single agent nivolumab in lung cancer patients. J Clin Oncol. (2018) 36:e21134. doi: 10.1200/JCO.2018.36.15_suppl.e21134

23. Chen Y, Guo Q, Lin J, Chen G, Pan LK, Wang Y, et al. Stereotactic body radiotherapy to extend the clinical benefit of PD-1 inhibitors in recurrent/metastatic nasopharyngel carcinoma. J Clin Oncol. (2018) 36:e18013. doi: 10.1200/JCO.2018.36.15_suppl.e18013

24. Antonia SJ, Villegas A, Daniel D, Vicente D, Murakami S, Hui R, et al. Durvalumab after chemoradiotherapy in stage III non-small-cell lung cancer. N Engl J Med. (2017) 377:1919-29. doi: 10.1056/NEJMoa1709937

25. Ferris RL, Blumenschein GR, Fayette J, Guigay J, Colevas AD, Licitra LF, et al. Further evaluations of nivolumab (nivo) versus investigator's choice (IC) chemotherapy for recurrent or metastatic (R/M) squamous cell carcinoma of the head and neck (SCCHN): CheckMate 141. J Clin Oncol. (2016) 34:6009. doi: 10.1200/JCO.2016.34.15_suppl.6009

26. Spranger S, Bao R, Gajewski TF. Melanoma-intrinsic beta-catenin signalling prevents anti-tumour immunity. Nature (2015) 523:231-5. doi: $10.1038 /$ nature 14404

27. Derer A, Spiljar M, Baumler M, Hecht M, Fietkau R, Frey B, et al. Chemoradiation increases PD-L1 expression in certain melanoma and glioblastoma cells. Front Immunol. (2016) 7:610. doi: 10.3389/fimmu.2016.00610

28. Rock KL, Lai JJ, Kono $H$. Innate and adaptive immune responses to cell death. Immunol Rev. (2011) 243:191-205. doi: 10.1111/j.1600-065X.2011.01040.x

29. Ishikawa H, Ma Z, Barber GN. STING regulates intracellular DNA-mediated, type I interferon-dependent innate immunity. Nature (2009) 461:788-92. doi: 10.1038 /nature 08476

30. Liu S, Cai X, Wu J, Cong Q, Chen X, Li T, et al. Phosphorylation of innate immune adaptor proteins MAVS, STING, and TRIF induces IRF3 activation. Science (2015) 347:aaa2630. doi: 10.1126/science.aaa2630

31. Deng L, Liang H, Xu M, Yang X, Burnette B, Arina A, et al. STING-dependent cytosolic DNA sensing promotes radiation-induced type I interferondependent antitumor immunity in immunogenic tumors. Immunity (2014) 41:843-52. doi: 10.1016/j.immuni.2014.10.019

32. Harlin H, Meng Y, Peterson AC, Zha Y, Tretiakova M, Slingluff C, et al. Chemokine expression in melanoma metastases associated with CD8+ T-cell recruitment. Cancer Res. (2009) 69:3077-85. doi: 10.1158/0008-5472.CAN-08-2281

33. Fuertes MB, Kacha AK, Kline J, Woo SR, Kranz DM, Murphy KM, et al. Host type I IFN signals are required for antitumor CD8+ T cell responses through CD8\{alpha\}+ dendritic cells. J Exp Med. (2011) 208:2005-16. doi: $10.1084 /$ jem.20101159

34. Burnette BC, Liang H, Lee Y, Chlewicki L, Khodarev NN, Weichselbaum RR, et al. The efficacy of radiotherapy relies upon induction of type i interferondependent innate and adaptive immunity. Cancer Res. (2011) 71:2488-96. doi: 10.1158/0008-5472.CAN-10-2820

35. Lim JY, Gerber SA, Murphy SP, Lord EM. Type I interferons induced by radiation therapy mediate recruitment and effector function of CD8(+) T cells. Cancer Immunol Immunother. (2014) 63:259-71. doi: $10.1007 / \mathrm{s} 00262-013-1506-7$

36. Liang H, Deng L, Hou Y, Meng X, Huang X, Rao E, et al. Host STINGdependent MDSC mobilization drives extrinsic radiation resistance. Nat Commun. (2017) 8:1736. doi: 10.1038/s41467-017-01566-5

37. Baird JR, Friedman D, Cottam B, Dubensky TW Jr, Kanne DB, Bambina S, et al. Radiotherapy combined with novel STINGtargeting oligonucleotides results in regression of established tumors. Cancer Res. (2016) 76:50-61. doi: 10.1158/0008-5472.CAN14-3619

38. Hou Y, Liang H, Rao E, Zheng W, Huang X, Deng L, et al. Non-canonical NFkappaB antagonizes STING sensor-mediated DNA sensing in radiotherapy. Immunity (2018) 49:490-503 e4. doi: 10.1016/j.immuni.2018.07.008

39. Wang SW, Sun YM. The IL-6/JAK/STAT3 pathway: potential therapeutic strategies in treating colorectal cancer (Review). Int J Oncol. (2014) 44:103240. doi: 10.3892/ijo.2014.2259

40. Yin Z, Ma T, Lin Y, Lu X, Zhang C, Chen S, et al. IL-6/STAT3 pathway intermediates M1/M2 macrophage polarization during the development of hepatocellular carcinoma. J Cell Biochem. (2018). 119:941932. doi: $10.1002 /$ jcb. 27259

41. Johnson DE, O'Keefe RA, Grandis JR. Targeting the IL-6/JAK/STAT3 signalling axis in cancer. Nat Rev Clin Oncol. (2018) 15:234-48. doi: $10.1038 /$ nrclinonc. 2018.8 
42. Stafford JH, Hirai T, Deng L, Chernikova SB, Urata K, West BL, et al. Colony stimulating factor 1 receptor inhibition delays recurrence of glioblastoma after radiation by altering myeloid cell recruitment and polarization. Neuro Oncol. (2016) 18:797-806. doi: 10.1093/neuonc/nov272

43. Chen D, Xie J, Fiskesund R, Dong W, Liang X, Lv J, et al. Chloroquine modulates antitumor immune response by resetting tumor-associated macrophages toward M1 phenotype. Nat Commun. (2018) 9:873. doi: 10.1038/s41467-018-03225-9

44. van Kooten C, Banchereau J. Functions of CD40 on B cells, dendritic cells and other cells. Curr Opin Immunol. (1997) 9:330-7. doi: 10.1016/S0952-7915(97)80078-7

45. Ridge JP, Di Rosa F, Matzinger P. A conditioned dendritic cell can be a temporal bridge between a CD4+ T-helper and a T-killer cell. Nature (1998) 393:474-8. doi: 10.1038/30989

46. Honeychurch J, Glennie MJ, Johnson PW, Illidge TM. Anti-CD40 monoclonal antibody therapy in combination with irradiation results in a CD8 T-cell-dependent immunity to B-cell lymphoma. Blood (2003) 102:1449-57. doi: 10.1182/blood-2002-12-3717

47. Matsumura S, Wang B, Kawashima N, Braunstein S, Badura M, Cameron TO, et al. Radiation-induced CXCL16 release by breast cancer cells attracts effector T cells. J Immunol. (2008) 181:3099-107. doi: 10.4049/jimmunol.181.5.3099

48. Meng Y, Efimova EV, Hamzeh KW, Darga TE, Mauceri HJ, Fu YX, et al. Radiation-inducible immunotherapy for cancer: senescent tumor cells as a cancer vaccine. Mol Ther. (2012) 20:1046-55. doi: 10.1038/mt.2012.19

49. Platten M, Wick W, Van den Eynde BJ. Tryptophan catabolism in cancer: beyond IDO and tryptophan depletion. Cancer Res. (2012) 72:5435-40. doi: 10.1158/0008-5472.CAN-12-0569

50. Munn DH, Mellor AL. IDO in the tumor microenvironment: inflammation, counter-regulation, and tolerance. Trends Immunol. (2016) 37:193-207. doi: 10.1016/j.it.2016.01.002

51. Mbongue JC, Nicholas DA, Torrez TW, Kim NS, Firek AF, Langridge WH. The role of indoleamine 2:3-dioxygenase in immune suppression and autoimmunity. Vaccines (2015) 3:703-29. doi: 10.3390/vaccines3030703

52. Liu H, Liu L, Liu K, Bizargity P, Hancock WW, Visner GA. Reduced cytotoxic function of effector CD8 $+\mathrm{T}$ cells is responsible for indoleamine 2,3dioxygenase-dependent immune suppression. J Immunol. (2009) 183:102231. doi: 10.4049/jimmunol.0900408

53. Spranger S, Spaapen RM, Zha Y, Williams J, Meng Y, Ha TT, et al. Up-regulation of PD-L1, IDO, and T(regs) in the melanoma tumor microenvironment is driven by CD8(+) T cells. Sci Transl Med. (2013) 5:200ral16. doi: 10.1126/scitranslmed.3006504

54. Mandai M, Hamanishi J, Abiko K, Matsumura N, Baba T, Konishi I, et al. Dual faces of IFNgamma in cancer progression: a role of PD-L1 induction in the determination of pro- and antitumor immunity. Clin Cancer Res. (2016) 22:2329-34. doi: 10.1158/1078-0432.CCR-16-0224

55. Ding Q, Lu P, Xia Y, Ding S, Fan Y, Li X, et al. CXCL9: evidence and contradictions for its role in tumor progression. Cancer Med. (2016) 5:324659. doi: 10.1002/cam4.934

56. Dong H, Strome SE, Salomao DR, Tamura H, Hirano F, Flies DB, et al. Tumor-associated B7-H1 promotes T-cell apoptosis: a potential mechanism of immune evasion. Nat Med. (2002) 8:793-800. doi: 10.1038/nm730

57. Lee SJ, Jang BC, Lee SW, Yang YI, Suh SI, Park YM, et al. Interferon regulatory factor-1 is prerequisite to the constitutive expression and IFN-gamma-induced upregulation of B7-H1 (CD274). FEBS Lett. (2006) 580:755-62. doi: 10.1016/j.febslet.2005.12.093

58. Gajewski TF, Schreiber H, Fu YX. Innate and adaptive immune cells in the tumor microenvironment. Nat Immunol. (2013) 14:1014-22. doi: $10.1038 /$ ni. 2703

59. Zhang $\mathrm{P}, \mathrm{Su} \mathrm{DM}$, Liang $\mathrm{M}, \mathrm{Fu}$ J. Chemopreventive agents induce programmed death-1-ligand 1 (PD-L1) surface expression in breast cancer cells and promote PD-L1-mediated T cell apoptosis. Mol Immunol (2008) 45:1470-6. doi: 10.1016/j.molimm.2007.08.013

60. Benci JL, Xu B, Qiu Y, Wu TJ, Dada H, Victor TSC, et al. Tumor interferon signaling regulates a multigenic resistance program to immune checkpoint blockade. Cell (2016) 167:1540-54 e12. doi: 10.1016/j.cell.2016. 11.022
61. Golden EB, Frances D, Pellicciotta I, Demaria S, Barcellos-Hoff HM, Formenti SC. Radiation fosters dose-dependent and chemotherapyinduced immunogenic cell death. Oncoimmunology (2014) 3:e28518. doi: 10.4161 /onci.28518

62. Ma Y, Adjemian S, Mattarollo SR, Yamazaki T, Aymeric L, Yang H, et al. Anticancer chemotherapy-induced intratumoral recruitment and differentiation of antigen-presenting cells. Immunity (2013) 38:729-41. doi: 10.1016/j.immuni.2013.03.003

63. Deaglio S, Robson SC. Ectonucleotidases as regulators of purinergic signaling in thrombosis, inflammation, and immunity. Adv Pharmacol. (2011) 61:30132. doi: 10.1016/B978-0-12-385526-8.00010-2

64. Ohta A, Kini R, Ohta A, Subramanian M, Madasu M, Sitkovsky M. The development and immunosuppressive functions of CD4(+) $\mathrm{CD} 25(+)$ FoxP3(+) regulatory $\mathrm{T}$ cells are under influence of the adenosine-A2A adenosine receptor pathway. Front Immunol. (2012) 3:190. doi: 10.3389/fimmu.2012.00190

65. Cekic C, Day YJ, Sag D, Linden J, Myeloid expression of adenosine A2A receptor suppresses $\mathrm{T}$ and $\mathrm{NK}$ cell responses in the solid tumor microenvironment. Cancer Res. (2014) 74:7250-9. doi: 10.1158/0008-5472.CAN-13-3583

66. Jobling MF, Mott JD, Finnegan MT, Jurukovski V, Erickson AC, Walian PJ, et al. Isoform-specific activation of latent transforming growth factor beta (LTGF-beta) by reactive oxygen species. Radiat Res. (2006). 166:83948. doi: 10.1667/RR0695.1

67. Chalmin F, Mignot G, Bruchard M, Chevriaux A, Vegran F, Hichami A, et al. Stat 3 and Gfi-1 transcription factors control Th17 cell immunosuppressive activity via the regulation of ectonucleotidase expression. Immunity (2012) 36:362-73. doi: 10.1016/j.immuni.2011.12.019

68. Ma SR, Deng WW, Liu JF, Mao L, Yu GT, Bu LL, et al. lockade of adenosine $\mathrm{A} 2 \mathrm{~A}$ receptor enhances CD8 $(+) \mathrm{T}$ cells response and decreases regulatory $\mathrm{T}$ cells in head and neck squamous cell carcinoma. Mol Cancer (2017) 16:99. doi: 10.1186/s12943-017-0665-0

69. Willingham SB, Ho PY, Hotson A, Hill C, Piccione EC, Hsieh J, et al. A2AR Antagonism with CPI-444 induces antitumor responses and augments efficacy to anti-PD-(L)1 and anti-CTLA-4 in preclinical models. Cancer Immunol Res. (2018) 6:1136-49. doi: 10.1158/2326-6066.CIR-18-0056

70. Allard B, Pommey S, Smyth MJ, Stagg J. Targeting CD73 enhances the antitumor activity of anti-PD-1 and anti-CTLA-4 mAbs. Clin Cancer Res. (2013) 19:5626-35. doi: 10.1158/1078-0432.CCR-13-0545

71. Wang L, Fan J, Thompson LF, Zhang Y, Shin T, Curiel TJ, et al. CD73 has distinct roles in non-hematopoietic and hematopoietic cells to promote tumor growth in mice. J Clin Invest. (2011) 121:2371-82. doi: 10.1172/JCI45559

72. Rodon J, Carducci MA, Sepulveda-Sanchez JM, Azaro A, Calvo E, Seoane $J$, et al. First-in-human dose study of the novel transforming growth factor-beta receptor I kinase inhibitor LY2157299 monohydrate in patients with advanced cancer and glioma. Clin Cancer Res. (2015) 21:553-60. doi: 10.1158/1078-0432.CCR-14-1380

73. Kovacs RJ, Maldonado G, Azaro A, Fernandez MS, Romero FL, SepulvedaSanchez JM, et al. Cardiac safety of TGF-beta receptor I kinase inhibitor LY2157299 monohydrate in cancer patients in a first-in-human dose study. Cardiovasc Toxicol. (2015) 15:309-23. doi: 10.1007/s12012-0149297-4

74. Morris JC, Tan AR, Olencki TE, Shapiro GI, Dezube BJ, Reiss M, et al. Phase I study of GC1008 (fresolimumab): a human anti-transforming growth factor-beta (TGFbeta) monoclonal antibody in patients with advanced malignant melanoma or renal cell carcinoma. PLoS ONE (2014) 9:e90353. doi: 10.1371/journal.pone.0090353

75. Lan Y, Zhang D, Xu C, Hance KW, Marelli B, Qi J, et al. Enhanced preclinical antitumor activity of $\mathrm{M7824}$, a bifunctional fusion protein simultaneously targeting PD-L1 and TGF-beta. Sci Transl Med. (2018) 10:eaan5488. doi: 10.1126/scitranslmed.aan5488

76. Kretschmar C, Oyarzun C, Villablanca C, Jaramillo C, Alarcon S, Perez $\mathrm{G}$, et al. Reduced adenosine uptake and its contribution to signaling that mediates profibrotic activation in renal tubular epithelial cells: implication in diabetic nephropathy. PLoS ONE (2016) 11:e0147430. doi: 10.1371/journal.pone.0147430 
77. Wennerberg E, Lhuillier C, Vanpouille-Box C, Pilones KA, Garcia-Martinez E, Rudqvist NP, et al. Barriers to radiation-induced in situ tumor vaccination. Front Immunol. (2017) 8:229. doi: 10.3389/fimmu.2017.00229

78. Moeller BJ, Cao Y, Li CY, Dewhirst MW. Radiation activates HIF-1 to regulate vascular radiosensitivity in tumors: role of reoxygenation, free radicals, and stress granules. Cancer Cell (2004) 5:429-41. doi: 10.1016/S1535-6108(04)00115-1

79. Kim YH, Yoo KC, Cui YH, Uddin N, Lim EJ, Kim MJ, et al. Radiation promotes malignant progression of glioma cells through HIF-1alpha stabilization. Cancer Lett. (2014) 354:132-41. doi: 10.1016/j.canlet.2014.07.048

80. Ishikawa $H$, Sakurai $H$, Hasegawa $M$, Mitsuhashi $N$, Takahashi $M$, Masuda N, et al. Expression of hypoxic-inducible factor lalpha predicts metastasis-free survival after radiation therapy alone in stage IIIB cervical squamous cell carcinoma. Int J Radiat Oncol Biol Phys. (2004) 60:513-21. doi: 10.1016/j.ijrobp.2004.03.025

81. Aebersold DM, Burri P, Beer KT, Laissue J, Djonov V, Greiner RH, et al. Expression of hypoxia-inducible factor-1alpha: a novel predictive and prognostic parameter in the radiotherapy of oropharyngeal cancer. Cancer Res. (2001) 61:2911-6.

82. Cramer T, Yamanishi Y, Clausen BE, Forster I, Pawlinski R, Mackman N, et al. HIF-1alpha is essential for myeloid cell-mediated inflammation. Cell (2003) 112:645-57. doi: 10.1016/S0092-8674(03)00154-5

83. Huang Y, Chen X, Dikov MM, Novitskiy SV, Mosse CA, Yang L, et al. Distinct roles of VEGFR-1 and VEGFR-2 in the aberrant hematopoiesis associated with elevated levels of VEGF. Blood (2007) 110:624-31. doi: 10.1182/blood-2007-01-065714

84. Gabrilovich D, Ishida T, Oyama T, Ran S, Kravtsov V, Nadaf S, et al. Vascular endothelial growth factor inhibits the development of dendritic cells and dramatically affects the differentiation of multiple hematopoietic lineages in vivo. Blood (1998) 92:4150-66.

85. Voron T, Colussi O, Marcheteau E, Pernot S, Nizard M, Pointet AL, et al. VEGF-A modulates expression of inhibitory checkpoints on CD8+ T cells in tumors. J Exp Med. (2015) 212:139-48. doi: 10.1084/jem.20140559

86. Barsoum IB, Smallwood CA, Siemens DR, Graham CH. A mechanism of hypoxia-mediated escape from adaptive immunity in cancer cells. Cancer Res. (2014) 74:665-74. doi: 10.1158/0008-5472.CAN-13-0992

87. Bajou K, Peng H, Laug WE, Maillard C, Noel A, Foidart JM, et al. Plasminogen activator inhibitor-1 protects endothelial cells from FasL-mediated apoptosis. Cancer Cell (2008) 14:324-34. doi: 10.1016/j.ccr.2008.08.012

88. Yang JY, Xia W, Hu MC. Ionizing radiation activates expression of FOXO3a, Fas ligand, and Bim, and induces cell apoptosis. Int J Oncol. (2006) 29:643-8. doi: 10.3892/ijo.29.3.643

89. Peter ME, Hadji A, Murmann AE, Brockway S, Putzbach W, Pattanayak A, et al. The role of CD95 and CD95 ligand in cancer. Cell Death Differ. (2015) 22:885-6. doi: 10.1038/cdd.2015.25

90. Motz GT, Santoro SP, Wang LP, Garrabrant T, Lastra RR, Hagemann IS, et al. Tumor endothelium FasL establishes a selective immune barrier promoting tolerance in tumors. Nat Med. (2014) 20:607-15. doi: 10.1038/nm.3541

91. Yu T, Tang B, Sun X. Development of inhibitors targeting hypoxiainducible factor 1 and 2 for cancer therapy. Yonsei Med J. (2017) 58:489-96. doi: 10.3349/ymj.2017.58.3.489

92. Kozakiewicz P, Grzybowska-Szatkowska L. Application of molecular targeted therapies in the treatment of head and neck squamous cell carcinoma. Oncol Lett. (2018) 15:7497-505. doi: 10.3892/ol.2018.8300

93. Jain RK, Duda DG, Clark JW, Loeffler JS. Lessons from phase III clinical trials on anti-VEGF therapy for cancer. Nat Clin Pract Oncol. (2006) 3:24-40. doi: $10.1038 /$ ncponc0403

94. Meadows KL, Hurwitz HI. Anti-VEGF therapies in the clinic. Cold Spring Harb Perspect Med. (2012) 2:a006577. doi: 10.1101/cshperspect.a006577

95. Sangroongruangsri S, Ratanapakorn T, Wu O, Anothaisintawee T, Chaikledkaew U. Comparative efficacy of bevacizumab, ranibizumab, and aflibercept for treatment of macular edema secondary to retinal vein occlusion: a systematic review and network meta-analysis. Expert Rev Clin Pharmacol. (2018) 11:903-16. doi: 10.1080/17512433.2018.1 507735
96. Li Q, Wu T, Jing L, Li MJ, Tian T, Ruan ZP, et al. Angiogenesis inhibitors for the treatment of small cell lung cancer (SCLC): a metaanalysis of 7 randomized controlled trials. Medicine (2017) 96:e6412. doi: 10.1097/MD.0000000000006412

97. Lombardi G, Pambuku A, Bellu L, Farina M, Della Puppa A, Denaro L, et al. Effectiveness of antiangiogenic drugs in glioblastoma patients: a systematic review and meta-analysis of randomized clinical trials. Crit Rev Oncol Hematol. (2017) 111:94-102. doi: 10.1016/j.critrevonc.2017.01.018

98. Roviello G, Bachelot T, Hudis CA, Curigliano G, Reynolds AR, Petrioli $\mathrm{R}$, et al. The role of bevacizumab in solid tumours: a literature based meta-analysis of randomised trials. Eur J Cancer (2017) 75:245-58. doi: 10.1016/j.ejca.2017.01.026

99. Sharma SP. Avastin saga reveals debate over clinical trial endpoints. J Natl Cancer Inst. (2012) 104:800-1. doi: 10.1093/jnci/djs265

100. Tomasek JJ, Gabbiani G, Hinz B, Chaponnier C, Brown RA. Myofibroblasts and mechano-regulation of connective tissue remodelling. Nat Rev Mol Cell Biol. (2002) 3:349-63. doi: 10.1038/nrm809

101. Rodemann HP, Muller GA. Characterization of human renal fibroblasts in health and disease: II. In vitro growth, differentiation, and collagen synthesis of fibroblasts from kidneys with interstitial fibrosis. Am J Kidney Dis. (1991) 17:684-6. doi: 10.1016/S0272-6386(12)80352-0

102. Simian M, Hirai Y, Navre M, Werb Z, Lochter A, Bissell MJ. The interplay of matrix metalloproteinases, morphogens and growth factors is necessary for branching of mammary epithelial cells. Development (2001) 128:3117-31.

103. Feig C, Jones JO, Kraman M, Wells RJ, Deonarine A, Chan DS, et al. Targeting CXCL12 from FAP-expressing carcinoma-associated fibroblasts synergizes with anti-PD-L1 immunotherapy in pancreatic cancer. Proc Natl Acad Sci USA. (2013) 110:20212-7. doi: 10.1073/pnas.1320318110

104. Kraman M, Bambrough PJ, Arnold JN, Roberts EW, Magiera L, Jones JO, et al. Suppression of antitumor immunity by stromal cells expressing fibroblast activation protein-alpha. Science (2010) 330:827-30. doi: $10.1126 /$ science. 1195300

105. Phillips RJ, Burdick MD, Hong K, Lutz MA, Murray LA, Xue YY, et al. Circulating fibrocytes traffic to the lungs in response to CXCL12 and mediate fibrosis. J Clin Invest. (2004) 114:438-46. doi: 10.1172/JCI200420997

106. Garcia-Albeniz X, Chan AT. Aspirin for the prevention of colorectal cancer. Best Pract Res Clin Gastroenterol. (2011) 25:461-72. doi: 10.1016/j.bpg.2011.10.015

107. Kuhnert F, Chen G, Coetzee S, Thambi N, Hickey C, Shan J, et al. Dll4 blockade in stromal cells mediates antitumor effects in preclinical models of ovarian cancer. Cancer Res. (2015) 75:4086-96. doi: 10.1158/0008-5472.CAN-14-3773

108. Jundt F, Anagnostopoulos I, Forster R, Mathas S, Stein H, Dorken B. Activated Notch1 signaling promotes tumor cell proliferation and survival in Hodgkin and anaplastic large cell lymphoma. Blood (2002) 99:3398-403. doi: 10.1182/blood.V99.9.3398

109. Kang J, Kim E, Kim W, Seong KM, Youn H, Kim JW, et al. Rhamnetin and cirsiliol induce radiosensitization and inhibition of epithelial-mesenchymal transition (EMT) by miR-34a-mediated suppression of Notch-1 expression in non-small cell lung cancer cell lines. J Biol Chem. (2013) 288:27343-57. doi: 10.1074/jbc.M113.490482

110. Kim RK, Kaushik N, Suh Y, Yoo KC, Cui YH, Kim MJ, et al. Radiation driven epithelial-mesenchymal transition is mediated by Notch signaling in breast cancer. Oncotarget (2016) 7:53430-42. doi: 10.18632/oncotarget.10802

111. Zhao Q, Mao A, Guo R, Zhang L, Yan J, Sun C, et al. Suppression of radiationinduced migration of non-small cell lung cancer through inhibition of Nrf2Notch Axis. Oncotarget (2017) 8:36603-13. doi: 10.18632/oncotarget.16622

112. Yadav A, Kumar B, Yu JG, Old M, Teknos TN, Kumar P. Tumorassociated endothelial cells promote tumor metastasis by chaperoning circulating tumor cells and protecting them from anoikis. PLoS ONE (2015) 10:e0141602. doi: 10.1371/journal.pone.0141602

113. Cabrera RM, S.Mao PH, Surve CR, Condeelis JS, Segall JE. A novel neuregulin - jagged1 paracrine loop in breast cancer transendothelial migration. Breast Cancer Res. (2018) 20:24. doi: 10.1186/s13058-018-0960-8

114. Barcellos-Hoff MH, Stromal mediation of radiation carcinogenesis. J Mammary Gland Biol Neoplasia (2010) 15:381-7. doi: 10.1007/s10911-010-9197-6 
115. Barker HE, Paget JT, Khan AA, Harrington KJ. The tumour microenvironment after radiotherapy: mechanisms of resistance and recurrence. Nat Rev Cancer (2015) 15:409-25. doi: 10.1038/nrc3958

116. Liu Y, Kudo K, Abe Y, Hu DL, Kijima H, Nakane A, et al. Inhibition of transforming growth factor-beta, hypoxia-inducible factor-1alpha and vascular endothelial growth factor reduced late rectal injury induced by irradiation. J Radiat Res. (2009) 50:233-9. doi: 10.1269/jrr.08112

117. Ohuchida K, Mizumoto K, Murakami M, Qian LW, Sato N, Nagai E, et al. Radiation to stromal fibroblasts increases invasiveness of pancreatic cancer cells through tumor-stromal interactions. Cancer Res. (2004) 64:3215-22. doi: 10.1158/0008-5472.CAN-03-2464

118. Straub JM, New J, Hamilton CD, Lominska C, Shnayder Y, Thomas SM. Radiation-induced fibrosis: mechanisms and implications for therapy. J Cancer Res Clin Oncol. (2015) 141:1985-94. doi: 10.1007/s00432-0151974-6

119. Sun YW, Zhang YY, Ke XJ, Wu XJ, Chen ZF, Chi P. Pirfenidone prevents radiation-induced intestinal fibrosis in rats by inhibiting fibroblast proliferation and differentiation and suppressing the TGFbeta1/Smad/CTGF signaling pathway. Eur J Pharmacol. (2018) 822:199-206. doi: 10.1016/j.ejphar.2018.01.027

120. Choi SH, Nam JK, Jang J, Lee HJ, Lee YJ. Pirfenidone enhances the efficacy of combined radiation and sunitinib therapy. Biochem Biophys Res Commun. (2015) 462:138-43. doi: 10.1016/j.bbrc.2015.04.107

121. Qin W, Liu B, Yi M, Li L, Tang Y, Wu B, et al. Antifibrotic agent pirfenidone protects against development of radiation-induced pulmonary fibrosis in a murine model. Radiat Res. (2018) 190:396-403. doi: 10.1667/RR15017.1

122. Shu HK, Yoon Y, Hong S, Xu K, Gao H, Hao C, et al. Inhibition of the CXCL12/CXCR4-axis as preventive therapy for radiation-induced pulmonary fibrosis. PLoS ONE (2013) 8:e79768. doi: 10.1371/journal.pone.0079768

123. Ferris RL, Blumenschein G Jr, Fayette J, Guigay J, Colevas AD, Licitra L, et al. Nivolumab vs investigator's choice in recurrent or metastatic squamous cell carcinoma of the head and neck: 2-year long-term survival updateof
CheckMate 141 with analyses by tumor PD-L1 expression. Oral Oncol. (2018) 81:45-51. doi: 10.1016/j.oraloncology.2018.04.008

124. Ventola CL. Cancer immunotherapy, part 2: efficacy, safety, and other clinical considerations. P T (2017) 42:452-63.

125. Weiner LM. Cancer immunology for the clinician. Clin Adv Hematol Oncol. (2015) 13:299-306.

126. Alatrash G, Jakher H, Stafford PD, Mittendorf EA. Cancer immunotherapies, their safety and toxicity. Expert Opin Drug Saf (2013) 12:631-45. doi: 10.1517/14740338.2013.795944

127. Corso CD, Ali AN, Diaz R. Radiation-induced tumor neoantigens: imaging and therapeutic implications. Am J Cancer Res. (2011) 1: 390-412.

128. Frey B, Ruckert M, Weber J, Mayr X, Derer A, Lotter M, et al. Hypofractionated irradiation has immune stimulatory potential and induces a timely restricted infiltration of immune cells in colon cancer tumors. Front Immunol. (2017) 8:231. doi: 10.3389/fimmu.2017. 00231

129. Hettich M, Lahoti J, Prasad S, Niedermann G. Checkpoint antibodies but not $\mathrm{T}$ cell-recruiting diabodies effectively synergize with TILInducing gamma-Irradiation. Cancer Res. (2016) 76:4673-83. doi: 10.1158/0008-5472.CAN-15-3451

Conflict of Interest Statement: The authors declare that the research was conducted in the absence of any commercial or financial relationships that could be construed as a potential conflict of interest.

Copyright (C) 2019 Darragh, Oweida and Karam. This is an open-access article distributed under the terms of the Creative Commons Attribution License (CC BY). The use, distribution or reproduction in other forums is permitted, provided the original author(s) and the copyright owner(s) are credited and that the original publication in this journal is cited, in accordance with accepted academic practice. No use, distribution or reproduction is permitted which does not comply with these terms. 